\title{
The Role of Cold Working in the Creep Deformation of Nb Stabilized Stainless Steel I. Creep Results and Microstructural Evolution
}

\author{
E. Evangelista ${ }^{1}$, C. Guardamagna ${ }^{2}$, L. Kloc ${ }^{3}$, A. Rosen $^{4}$ and S. Spigarelli ${ }^{1}$ \\ ${ }^{1}$ Department of Mechanics, University of Ancona, 1-60131 Ancona, Italy \\ ${ }^{2}$ ENEL CRAM, Via Monfalcone 15, 1-20132 Milano, Italy \\ ${ }^{3}$ Institute of Physics of Materials, Brno, Czech 'Republic \\ ${ }^{4}$ Department of Materials Engineering, Technion, Haifa 32000, Israel.
}

\begin{abstract}
The effect of cold working on the creep strength and microstructural evolution of an AISI 347 stainless steel during creep was studied between 625 and $825^{\circ} \mathrm{C}$. The relationship between the minimum creep rate, the stress and the temperature was obtained by best fitting of the experimental data. The microstructural parameters (average dimension of the particles, number of precipitates per unit volume, dislocation density) were measured in samples crept up to rupture as well as after interrupted tests; the Orowan stress obtained from microstructural data was related to the rupture dislocation density. The effect of prestraining on the deformation-time curve was found to be different from the one observed in other stainless steels. These results and the microstructural observations suggested that the precipitation of fine $\mathrm{NbC}$ played an important role in reducing the kinetics of the recovery processes.
\end{abstract}

\section{INTRODUCTION}

The effect of prestrain on the creep properties of several materials was extensively studied $/ 1-5 /$. Cold working introduces a high initial dislocation density, which in austenitic stainless steels generally gives rise to a substantial increase in creep strength and rupture life. The evolution of dislocation density during creep of a coarse grained material $/ 6 /$ showed an initial strong increase in the free dislocation content (free dislocations being the fraction of dislocation population not arranged in subgrains) followed by the re-arrangement of the dislocations in networks, and subsequently in subgrain boundaries. Extensive research has been carried out in order to understand the creep mechanisms in class $M$ materials (pure metals and single phase alloys), in which creep deformation is recovery-controlled $/ 7,8 /$. Recovery creep was explained in terms of the interaction of strain hardening and recovery processes, leading to the formation of a threedimensional network of dislocations. The high creep strength shown in cold worked AISI 304 /5/ or Fe$21 \mathrm{Cr}-32 \mathrm{Ni} / 4 /$, for example, was attributed mainly to the entanglement of dislocations into a three-dimensional network of dislocations (Taylor hardening); nevertheless, the precipitation of fine $\mathrm{M}_{23} \mathrm{C}_{6}$ on dislocations was observed for long exposure times in not prestrained as well as in cold worked materials $19,10 \%$. When precipitation occurred in these simple austenitic stainless steels, secondary creep was thought to be controlled by particle-dislocation interaction, while primary creep was associated with different phenomena, such as the formation of planar arrays of dislocation, the viscous drag of $\mathrm{Cr}$ and $\mathrm{C}$ solute atoms and piling up of the line defects $/ 9 /$.

The study of the creep response becomes even more complex in the $\mathrm{Nb}$ or $\mathrm{Ti}$ bearing stainless steels. These 
steels are stabilized against $\mathrm{Cr}$ carbide precipitation (sensitization) by small additions of $\mathrm{Nb}$ or $\mathrm{Ti}$, so that when tested in the solutioned state, an extensive precipitation of fine $\mathrm{Nb}$ or $\mathrm{Ti}$ carbides nucleated on dislocations is invariably observed $/ 3,11-14 /$. On this basis, the improved creep behaviour of the solutiontreated and stabilized material was attributed to the particle strengthening mechanisms $/ 3,11,15-19 /$; moreover, when the material was prestrained before aging or creep, a significant increase both in the precipitation kinetics as well as in creep strength was observed $/ 3,11,13,19 /$.

This study aims to evaluate the effect of a prestraining on the creep response and on the microstructural evolution of the AISI 347 stainless steel.

\section{MATERIAL AND EXPERIMENTAL}

The material used in this study was AISI 347. This steel, supplied in the form of extruded tubes in a solution-treated condition $\left(1120^{\circ} \mathrm{C}-45 \mathrm{~min}\right)$, had the following chemical composition (weight \%): $17.3 \mathrm{Cr}$, $10.4 \mathrm{Ni}, 0.048 \mathrm{C}, 0.52 \mathrm{Nb},<0.01 \mathrm{Ta}$, Fe balance.

Creep specimens with a gauge length of $50 \mathrm{~mm}$ were machined from the tube and then cold worked in tension up to 5,10 or $15 \%$ plastic deformation; before creep the samples were remachined up to the final diameter of $5 \mathrm{~mm}$.

The constant-load creep tests were carried out in air at a temperature between 625 and $825^{\circ} \mathrm{C}$ under stresses of 50,127, 157 and $196 \mathrm{MPa}$; some of the tests carried out at $650^{\circ} \mathrm{C}$ and $157 \mathrm{MPa}$ were interrupted after 24 , 120 or $600 \mathrm{~h}$ and cooled under load.

A detailed characterization of the microstructure was performed by TEM; slices cut with a diamond saw at $45^{\circ}$ to the longitudinal direction of the crept samples were ground to a thickness of $200 \mu \mathrm{m}$, and then electropolished to $50 \mu \mathrm{m}$ thickness with a $10 \%$ perchloric acid in an ethylene glycol solution at $12^{\circ} \mathrm{C}$ and $25 \mathrm{~V}$. Thin foils were subsequently obtained by double jet in the same solution.

The number of particles per unit volume $N_{v}$ was estimated by an image analysis system; the dislocation density $\rho$ was measured on TEM micrographs by the intercept method. The Orowan stress was estimated from the equation $/ 20,21 /$

$$
\sigma_{O R}=3.06 \frac{0.01 \sigma^{2}}{2 \pi \lambda \sqrt{1-v}} \ln \left(\frac{d s}{\frac{d}{b}}\right)
$$

where $G$ is the shear modulus, $b$ is the Burgers' vector, $v$ is the Poisson ratio, $\lambda$ is the mean interparticle spacing calculated from $\mathrm{N}_{\mathrm{v}}$ and the average dimension of the particles $d / 20 /$ and $d_{s}=d(2 / 3)^{0.5}$.

\section{RESULTS}

\section{Creep Results}

The creep curves shown in Fig. 1 illustrate an example of the effect of cold working (c.w.) on creep deformation observed between 625 and $725^{\circ} \mathrm{C}$. The prestraining induced a substantial reduction in the minimum creep rate $\left(\dot{\varepsilon}_{m}\right)$, an increase in the time to rupture $\left(t_{R}\right)$ (Figs. 2-3 and Table 1 ) and a dramatic decrease in the rupture ductility.

The minimum creep rate was related to stress and temperature by the equation:

$$
\epsilon_{m}=A \sigma^{n} e^{-Q} R T
$$

where $Q$ is the apparent activation energy for creep, $R$ the gas constant, $T$ the absolute temperature and $A$ and n parameters depending on the material. The apparent activation energy for creep was found to show a weak dependence on cold working amount $/ 22 /$, the average value being $434 \mathrm{~kJ} / \mathrm{mol}$. This is fully comparable with the value of $398-464 \mathrm{~kJ} / \mathrm{mol}$ obtained in other austenitic stainless steels strengthened by $\mathrm{NbC}$ particles /11/. The stress exponent $n$ was $8.8,6.8$ and 4.9 for as received (a.r.), $5 \%$ cold worked (c.w.) and $15 \%$ c.w. materials, respectively; a similar decrease in $n$ as the amount of cold work increased was also observed for the $20 \mathrm{Cr}$ $25 \mathrm{Ni}-\mathrm{Nb}$ stainless steel $/ 3 /$.

The minimum creep rate and the time to fracture were related by the Dobes - Milicka equation /23/:

$$
\log \left(\frac{t_{R}}{\epsilon_{R}}\right)+m \log \epsilon_{m}=C
$$




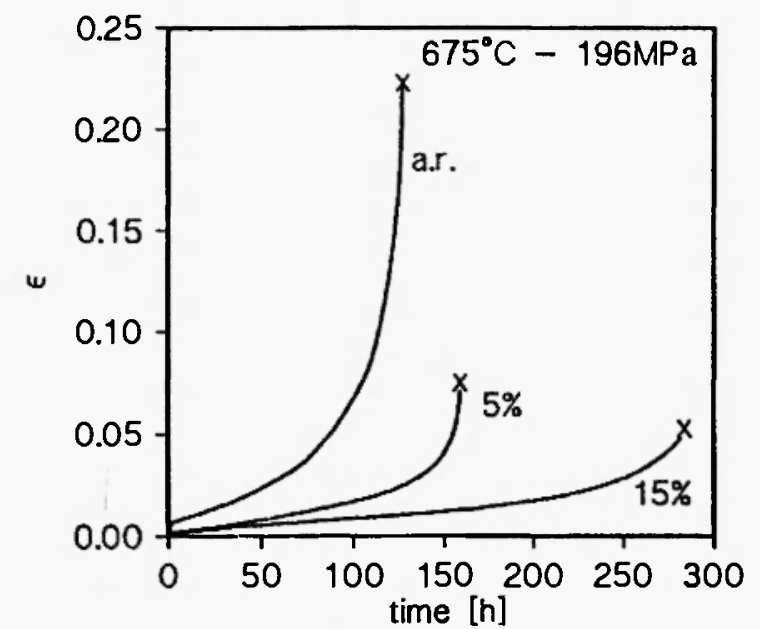

Fig. 1: Creep-rupture curves at $675^{\circ} \mathrm{C}-196 \mathrm{MPa}$ for the as-received, 5 and $15 \%$ cold worked samples.

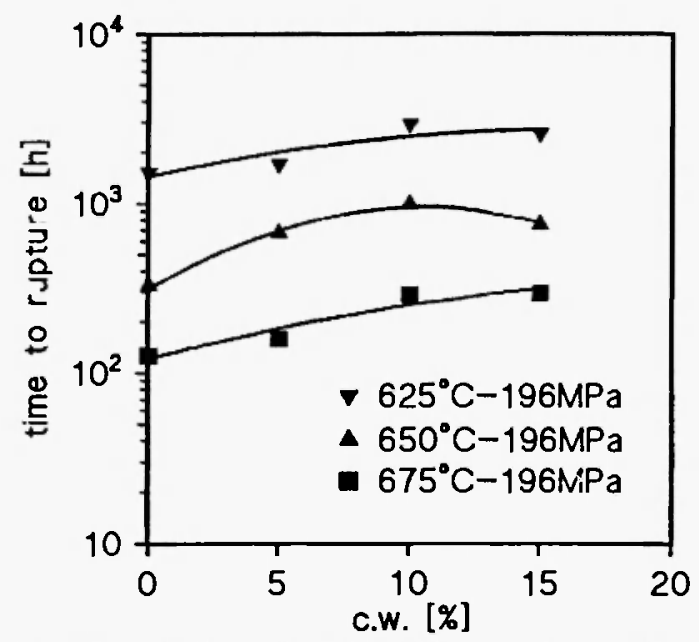

Fig. 2: Effect of cold working on time to fracture.

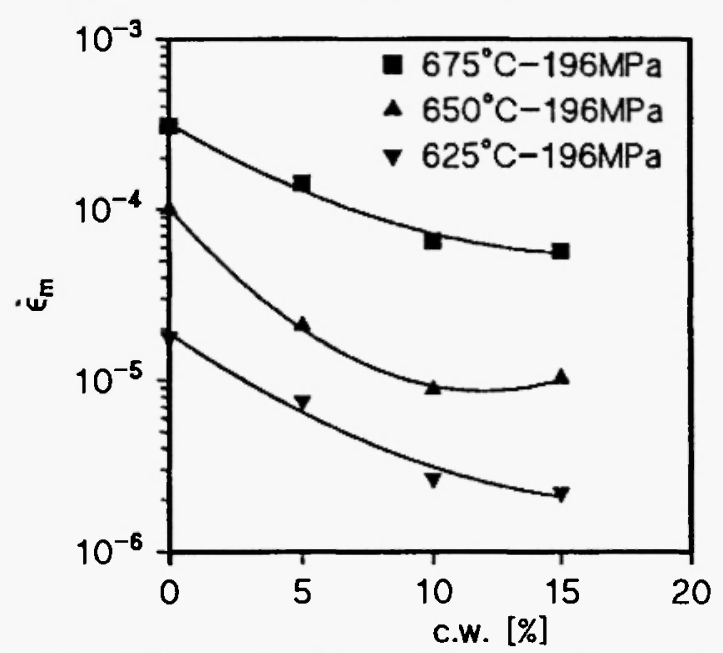

Fig. 3: Effect of cold working on the minimum creep rate.

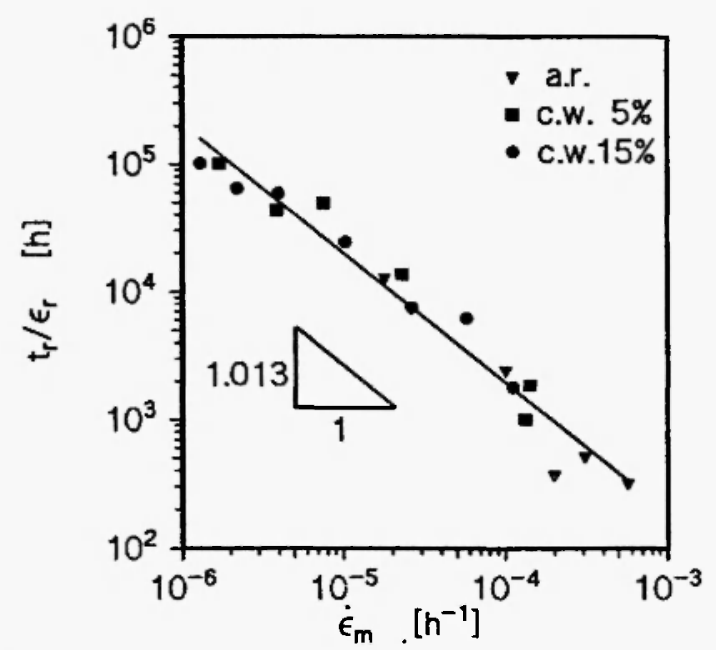

Fig. 4: Dependence of ratio of time to fracture to total creep deformation on minimum creep rate.

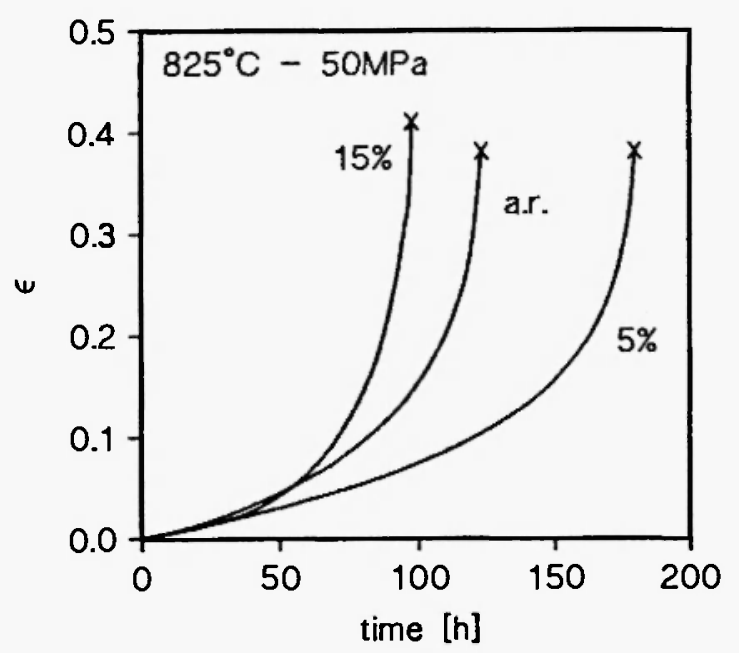

Fig. 5: Effect of cold working on the shape of the creep curve at $825^{\circ} \mathrm{C}$.

where $\varepsilon_{\underline{p}}$ is the deformation at rupture, and $C$ and $m$ ( $m$ usually close to 1) are material parameters. The computed value of $m$ is 1.013 (Fig. 4); the proportionality of the product of minimum creep rate and time to fracture to the total creep deformation could be considered, as shown by Dobes and Milička /23/, a confirmation of the deformation dependence of rupture processes.

The trend of the experimental creep curves recorded at $825^{\circ} \mathrm{C}$ and $50 \mathrm{MPa}$ is reported in Fig. 5: the $15 \%$ c.w. creep curve after $20 \mathrm{~h}$ showed an increase of creep rate that led to a shorter time to rupture. Moreover, the relatively large strain to fracture (about 40\%) is practically unaffected by c.w. 
Table 1

Minimum creep rate and time to rupture obtained fo: as-received, 5 and $15 \%$ c.w. samples

\begin{tabular}{|c|c|c|c|c|}
\hline c.w. $\%$ & $\mathrm{~T}\left[{ }^{\circ} \mathrm{C}\right]$ & $\sigma \quad[\mathrm{MPa}]$ & $\mathrm{t}_{\mathrm{R}}[\mathrm{h}]$ & $\varepsilon_{m}\left[10^{-6} h^{-1}\right]$ \\
\hline \multirow[t]{6}{*}{$\overline{0}$} & 625 & 196 & 1539 & 18 \\
\hline & 650 & 196 & 327 & 100 \\
\hline & 675 & 196 & 126 & 309 \\
\hline & 700 & 127 & 411 & 35.2 \\
\hline & 725 & 127 & 120 & 200 \\
\hline & 825 & 50 & 123 & 568 \\
\hline \multirow[t]{9}{*}{5} & 625 & 196 & 1714 & 7.56 \\
\hline & 650 & 196 & 675 & 20 \\
\hline & 650 & 157 & 1922 & 3.9 \\
\hline & 650 & 127 & 4200 & 1.7 \\
\hline & 675 & 196 & 159 & 142 \\
\hline & 700 & 196 & 58 & 425 \\
\hline & 700 & 127 & 535 & 20.3 \\
\hline & 725 & 127 & 128 & 133 \\
\hline & 825 & 50 & 180 & 465 \\
\hline \multirow[t]{11}{*}{15} & 625 & 196 & 2597 & 2.21 \\
\hline & 650 & 196 & 794 & 12.3 \\
\hline & 650 & 196 & 777 & 9.5 \\
\hline & 650 & 196 & 699 & 9.1 \\
\hline & 650 & 157 & 1670 & 4.0 \\
\hline & 650 & 127 & 5107 & 1.3 \\
\hline & 675 & 196 & 298 & 57.6 \\
\hline & 700 & 196 & 78 & 236 \\
\hline & 700 & 127 & 604 & 26.3 \\
\hline & 725 & 127 & 260 & 112 \\
\hline & 825 & 50 & 98 & 297 \\
\hline
\end{tabular}

\section{Microstructure}

Fig. 6 shows the microstructure of the as-received material obtained directly from the tube: large $\mathrm{Nb}$-rich primary particles, associated with dislocation tangles, were dispersed in the matrix. After prestraining, the dislocation density dramatically increased $\left(\rho>10^{14} \mathrm{~m}^{-2}\right)$.

The microstructure after creep rupture at $196 \mathrm{MPa}-$ $650^{\circ} \mathrm{C}$ is shown in Fig. 7: an extremely high dislocation density still persisted after $t>1000 \mathrm{~h}$, and recovery was far from complete. At a higher magnification, there was evidence of a fine precipitation of $\mathrm{NbC}$ particles decorating line defects.

The interrupted tests were used to investigate the microstructural evolution during creep exposure at $650^{\circ} \mathrm{C}$ (Figs. 8-10 and Table 2). Between 24 and $120 \mathrm{~h}$,

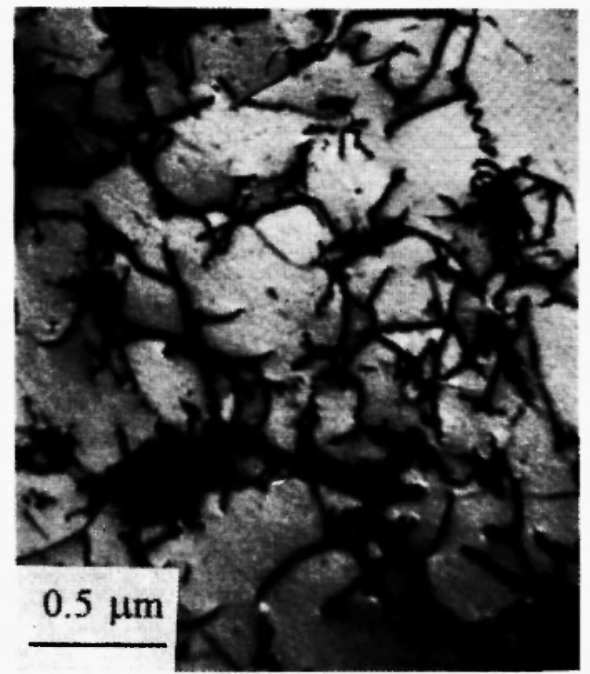

Fig. 6: Microstructure of the as-received material. 


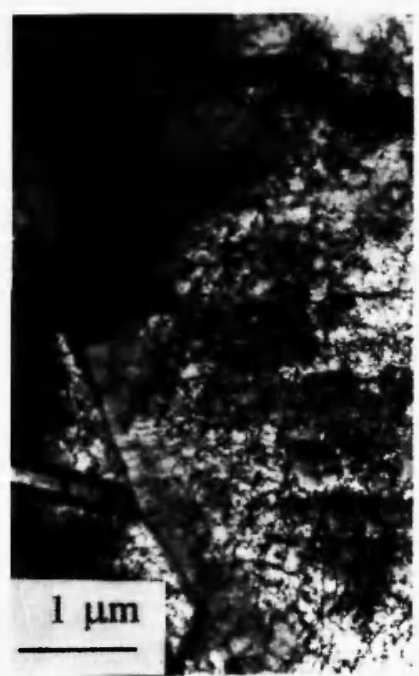

a)

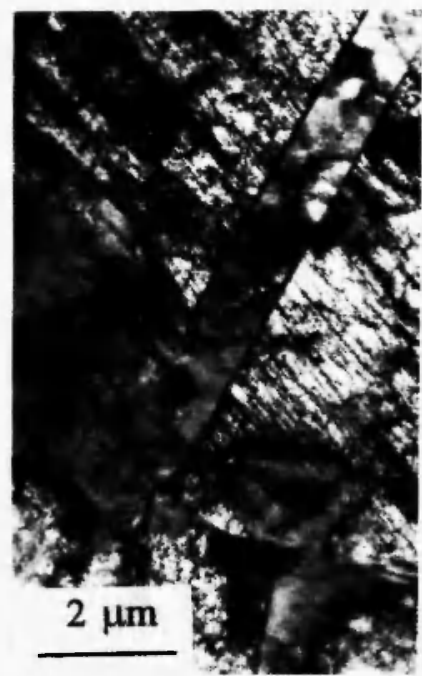

b)

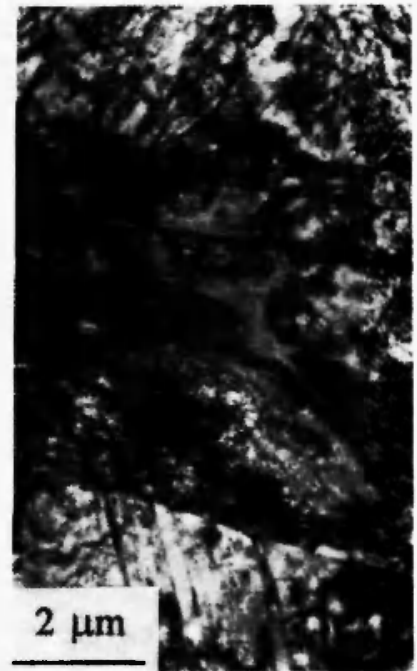

c)

Fig. 7: Microstructure of the crept sample at $650^{\circ} \mathrm{C}-196 \mathrm{MPa}$ a) as received; b) c.w. $5 \%$; c) c.w. $15 \%$.

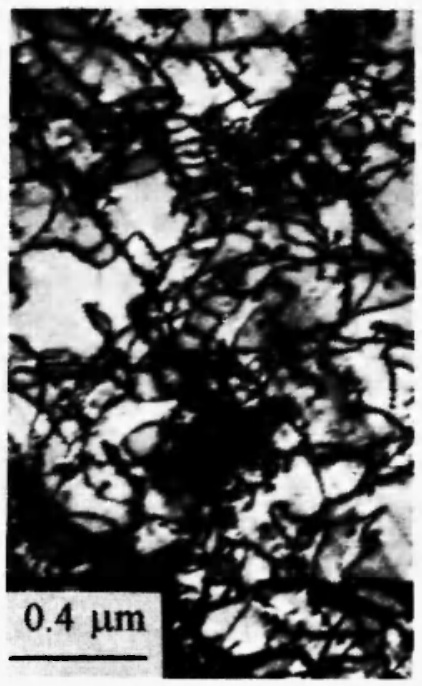

a)

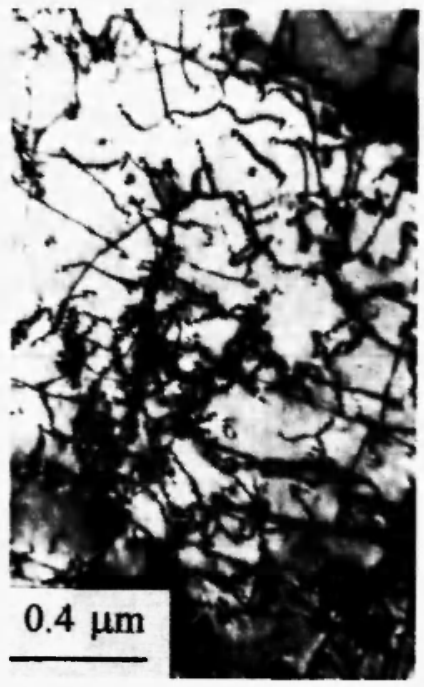

b)

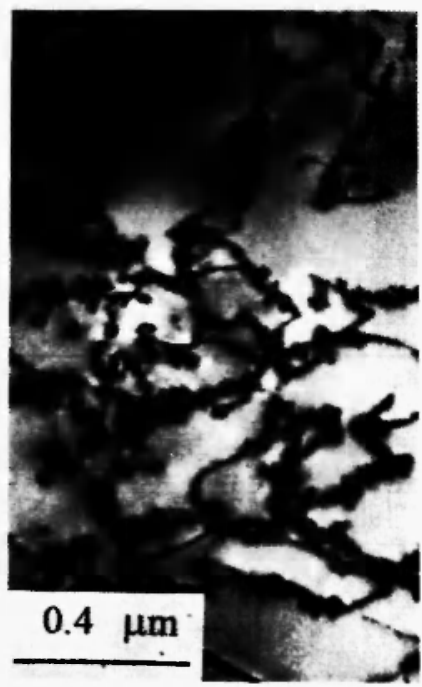

c)

Fig. 8: Microstructure of the as received material during creep at $650^{\circ} \mathrm{C}-157 \mathrm{MPa}$; a) $24 \mathrm{~h}$; b) $120 \mathrm{~h}$; c) $600 \mathrm{~h}$.

the dislocation density progressively increased, reaching a maximum, and at the same time fine particles began to nucleate on dislocations (Figs. 8-10 a and b). After $120 \mathrm{~h}$, the dislocation density dropped, and in the as-received as well as in 5\% c.w. samples growth of the intragranular particles was observed. In the $15 \%$ c.w. material the dimension of the $\mathrm{NbC}$ did not increase significantly between 120 and $600 \mathrm{~h}$; it should be pointed out that in the highly prestrained samples the number of particles per unit volume shown in Table 2 was probably underestimated, due to the difficulty in unambiguously identifying the finest particles (size < $10 \mathrm{~nm}$ )

Fig. 11 shows the microstructure after rupture at $825^{\circ} \mathrm{C}$; a very well defined substructure appeared, the dislocation density being very low both in a.r. and in $15 \%$ c.w. materials. The dimension of secondary intragranular particles was finer in the $15 \%$ prestrained 


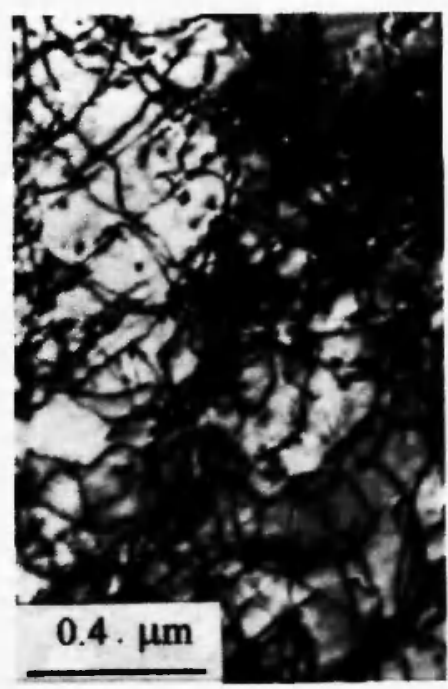

a)

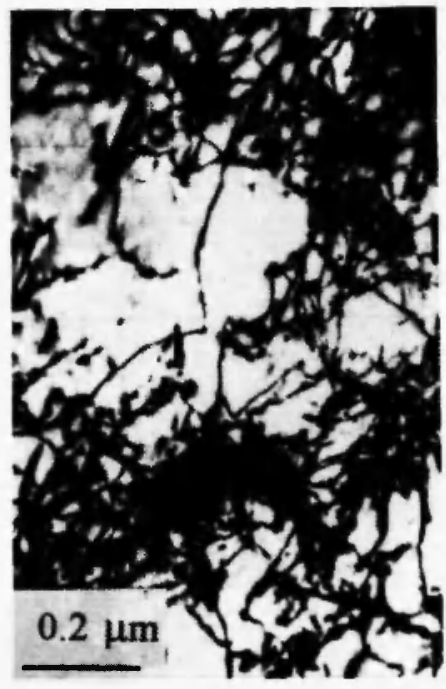

b)

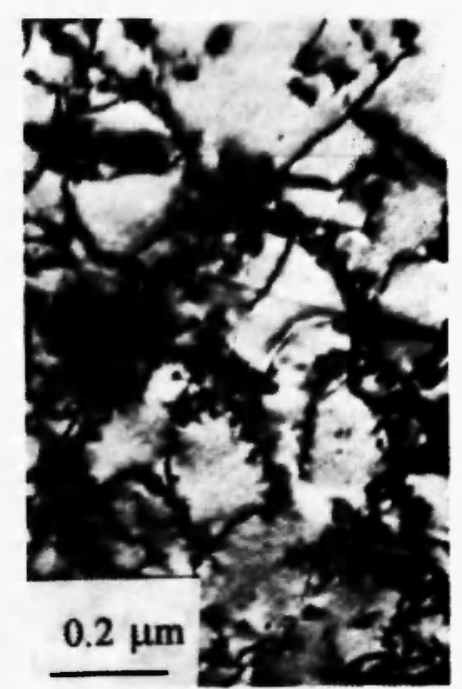

c)

Fig. 9: Microstructure of the $5 \%$ c.w. material during creep at $650^{\circ} \mathrm{C}-157 \mathrm{MPa}$; a) $24 \mathrm{~h}$; b) $120 \mathrm{~h}$; c) $600 \mathrm{~h}$.

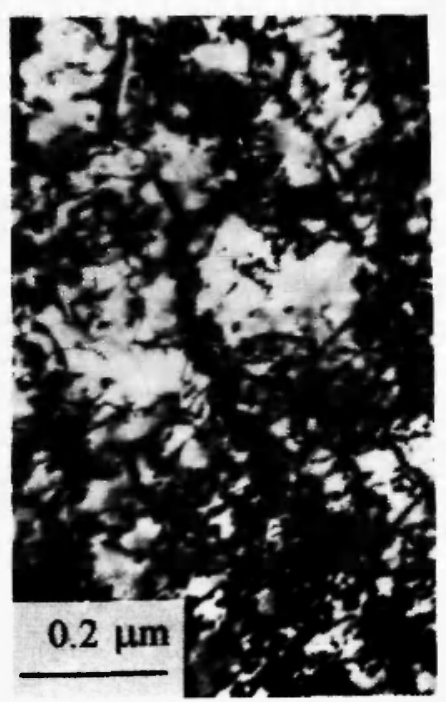

a)

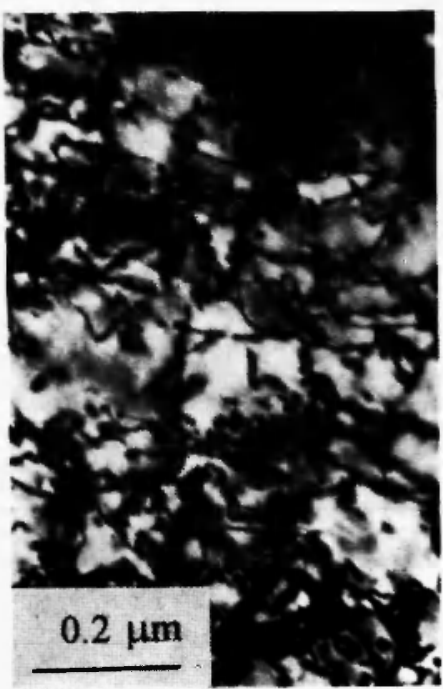

b)

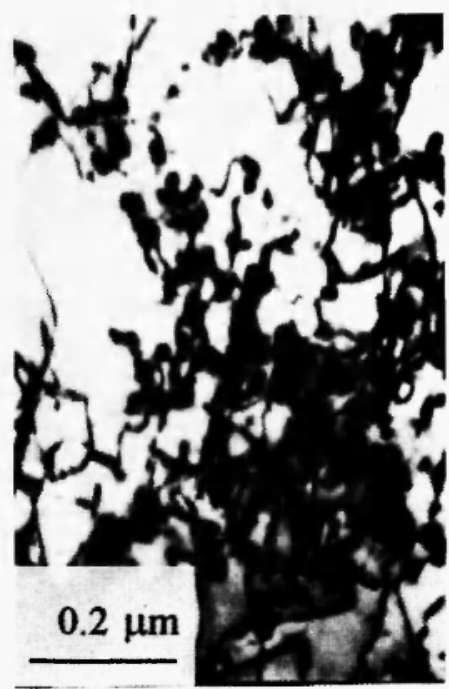

c)

Fig. 10: Microstructure of the $15 \%$ c.w. material during creep at $650^{\circ} \mathrm{C}-157 \mathrm{MPa}$; a) $24 \mathrm{~h}$; b) $120 \mathrm{~h}$; c) rupture.

sample, and precipitation was slightly more extensive than in the as-received and crept material. The high test temperature and the high initial dislocation density in $15 \%$ c.w. steel made the recovery processes very fast, producing a substructure that was roughly equivalent to the as-received one; this softening resulted in a gradual loss of creep strength and in the early onset of accelerated creep. On the other hand, the higher dislocation density in the subgrain interior in the $5 \%$ c.w. material after rupture gave evidence of a reduced driving force for annealing. The high creep strength of the $5 \% \mathrm{c.w}$. observed at this temperature could consequently be explained in terms of microstructural stability, i.e., slower kinetics of recovery. 
Table 2

Microstructural parameters obtained from interrupted tests at $650^{\circ} \mathrm{C}-157 \mathrm{MPa}$.

\begin{tabular}{cccc}
\hline c.w. & time $[\mathrm{h}]$ & $\rho\left[10^{14} \mathrm{~m}^{-2}\right]$ & $\mathrm{N}_{\mathrm{v}}\left[10^{21} \mathrm{~m}^{-3}\right]$ \\
\hline 0 & 24 & 2.04 & $>0.04$ \\
& 120 & 2.62 & 0.5 \\
& 600 & 1.00 & 0.3 \\
\hline 5 & 24 & 3.52 & $>0.1$ \\
& 120 & 4.58 & 0.6 \\
& 600 & 2.52 & 0.8 \\
\hline 15 & 24 & 4.27 & $>0.4$ \\
& 120 & 5.43 & $>0.9$ \\
& 600 & 4.46 & $>1.0$ \\
\hline \hline
\end{tabular}

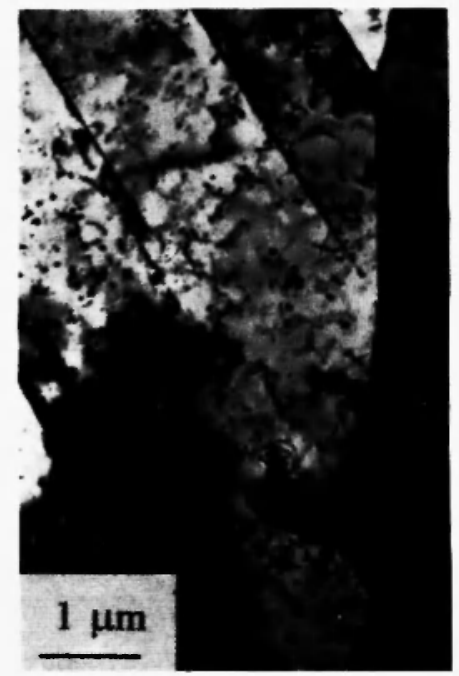

a)

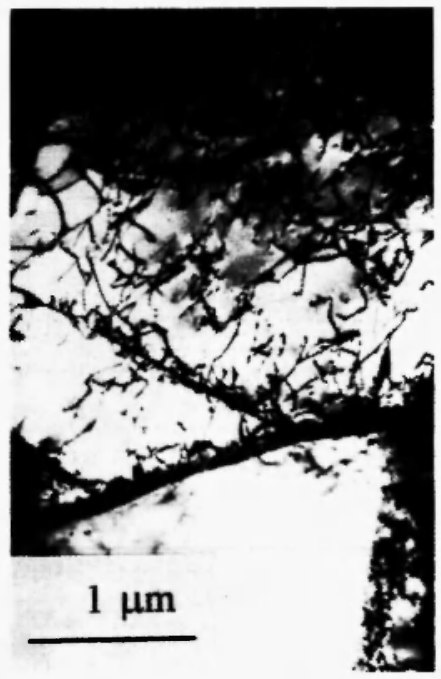

b)

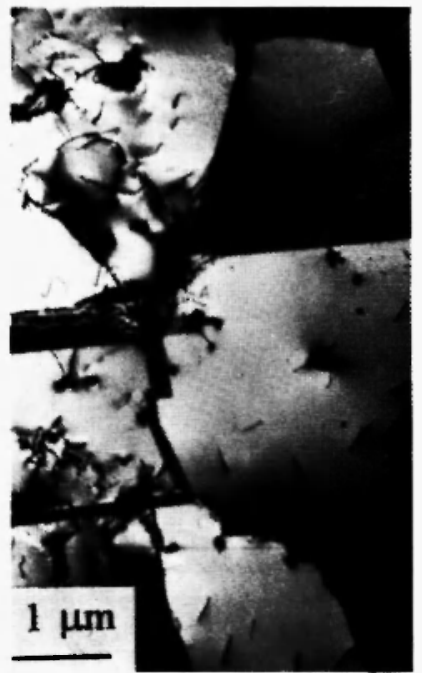

c)

Fig. 11: Microstructure of the sample crept at $825^{\circ} \mathrm{C}-50 \mathrm{MPa}$; a) a.r.; b) $5 \%$ c.w.; c) $15 \%$ c.w.

\section{DISCUSSION}

Both recovery and particle growth were observed to be relatively slow in the highly prestrained material between 625 and $725^{\circ} \mathrm{C}$. Kesternich $/ 19 /$ showed a similar effect in a $15 \%$ c.w. DIN 1.4970 steel. The decrease in $\mathrm{TiC}$ dimension as c.w. increased was attributed by the author to an increase in the number of nucleation sites and to a reduction in dislocation mobility. In fact, the dislocations, dragging the Cottrell atmosphere, generated a local supersaturation of solute atoms at the point where the dislocations interacted, leading to the nucleation of particles; a significant increase in the particle dimension was observed only as long as the growth was assisted by the mobile dislocations (recovery-controlled growth). A high initial dislocation density was produced by prestraining enhanced nucleation of fine particles that pinned the dislocations, reducing the kinetics of recovery. On the other hand, when the initial dislocation density was low, the effectiveness of particle nucleation was reduced, and as a result the particle pinning effect was also reduced. In this sense nucleation was promoted in the prestrained samples, while recovery-controlled 
growth $/ 19 /$ was promoted in the as-received material.

In order to relate the dislocation density to the characteristics of particle distribution, the Orowan stress obtained at rupture at $625^{\circ} \mathrm{C}-196 \mathrm{MPa}, 650^{\circ} \mathrm{C}$ $196 \mathrm{MPa}$ and $725^{\circ} \mathrm{C}-127 \mathrm{MPa}$ was reported as a function of $\mathrm{Gb}(\rho)^{0.5}$ (Fig. 12). The correlation between the two parameters at 625 and $650^{\circ} \mathrm{C}$ was sought in the form

$$
\sigma_{O R}=\alpha G b \sqrt{\rho}
$$

The calculated value of the constant $\alpha$ was 0.95 . Equation 4 is formally similar to the relationship proposed by Ecob $/ 16 /$ to relate the Orowan stress to the "irrecoverable dislocation density" $\rho_{0}$ (i.e., a threshold dislocation content that depends on the particle distribution, and is equivalent to the annealed in dislocation density). The value of $\rho_{0}$ is such that the average dislocation link length is approximately equal to $\lambda / 17 /$; according to Ecob, when the applied stress is lower or close to the Orowan stress, the free dislocation density during the secondary and tertiary stage is constant and equal to $\rho_{0}$. Senior $/ 15 /$ reported a similar behaviour in an AISI 347 tested at $650^{\circ} \mathrm{C}$. The data obtained in the present study at $650^{\circ} \mathrm{C}$ from the interrupted tests were consistent with this theory; during primazy creep the recovery processes reduced

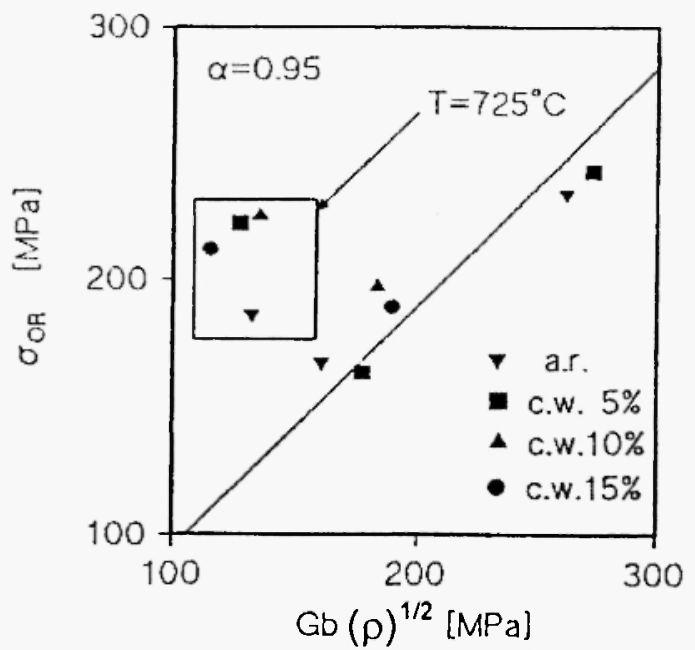

Fig. 12: Relationship between the Orowan stress and the dislocation density measured at fracture; the data obtained at $725^{\circ} \mathrm{C}$ were not used in the calculation of the $\alpha$ constant. the dislocation content, increasing the mean dislocation link length $\mathrm{L} \propto(p)^{-0.5}$ in the network $/ 24 /$. When $\mathrm{L}$ becomes equal to the interparticle spacing $\lambda$, the recovery processes are obstructed by the particledislocation interaction and the dislocation content remains almost constant up to rupture; then, with $\lambda=\mathrm{L}$ $\propto(\rho)^{-0.5}$, the following equation is obtained $/ 16 /$ :

$$
\sigma_{O R} \propto \frac{G b}{\lambda} \approx \alpha G b \sqrt{\rho}
$$

where $\alpha$ is a geometrical factor close to 1 . Nevertheless, at $725^{\circ} \mathrm{C}$ the experimental data lie well above the line that represents Eqns. 4-5; this result suggests that at high temperature the microstructural evolution was somewhat different from that at 625 and $650^{\circ} \mathrm{C}$. This behaviour was much more evident at $825^{\circ} \mathrm{C}$, where the distribution and dimension of the fine $\mathrm{NbC}$ particles were found similar in the a.r. and $15 \%$ c.w. materials $\left(\mathrm{N}_{\mathrm{v}}\right.$ was indeed 'slightly larger in the prestrained sample), while the subgrain interior was practically dislocation-free. At a high temperature, recovery of highly prestrained materials is very fast, and combination of the different processes of recovery of dislocation substructures-nucleation and growth of the $\mathrm{NbC}$ results in very well defined substructures and relatively large particles.

The lower minimum creep rate, shown by the $15 \%$ prestrained material with respect to the a.r. and 5\% c.w. ones between 625 and $725^{\circ} \mathrm{C}$, could be attributed mainly to Taylor hardening $/ 5 /$ and/or to the extensive precipitation of fine particles (particle strengthening) $111,22 /$. Nevertheless, the creep behaviour of this material was the result of a complex balance of different and sometimes simultaneous and interlaying mechanisms:

i) the introduction of a high dislocation density due to prestraining, which results in the formation of a relatively stable network of dislocations (Taylor hardening);

ii) the recovery processes due to the high temperature, and the subsequent formation of substructures and reduction of the free dislocation density;

iii) the precipitation of fine $\mathrm{NbC}$, which nucleated on dislocations and obstructed the mobility of 
the line defects, reducing the kinetics of recovery;

iv) the drop of the amount of elements in solid solution (mainly $\mathrm{Nb}$ and $\mathrm{C}$ ) that occurred in parallel with precipitation, resulting in the reduction of solid solution strengthening;

v) the growth of the fine particles, that led to an increase in particle spacing and to a reduction of the particle strengthening effect.

Creep Deformation in the As-Received (SolutionTreated) Material

Fig. 13 shows an interesting comparison between the a.r. creep response observed in this study and the creep curves reported by Senior $/ 15 /$ under similar test conditions for an AISI 347 after solution treatment and $750^{\circ} \mathrm{C} \times 200 \mathrm{~h}$ aging. After an extremely fast (typically $10 \mathrm{~h}$ at $650^{\circ} \mathrm{C}$ ) decrease in the creep rate, the solutiontreated (a.r.) and crept material showed a pseudotertiary response (i.e., a continuous, even if very slow, increase in the creep rate). During the very early stage of creep deformation $(t<50 \mathrm{~h})$, a relatively high content of $\mathrm{Nb}$ and $\mathrm{C}$ was retained in solid solution; on the other hand, the results of measurements of dislocation density suggested that $\rho$ increased, reaching a maximum between 24 and $120 \mathrm{~h}$. On this basis, the onset of the pseudo-tertiary creep could perhaps be attributed to a class A (solid solution) creep behaviour (both dislocation density and strain rate increased with time). As deformation (and time) proceeded, precipitation occurred (Fig. 8) and the solid solution strengthening lost its effectiveness; moreover, the dislocation density dropped (Table 2) and creep became recovery-controlled (class $M$ ). The slow increase in creep rate after $100 \mathrm{~h}$, in this case, could be attributed to different phenomena (i.e., coarsening of the particles, reduction in the fraction of mobile dislocation density). The comparison in Fig. 13, on the other hand, shows that aging considerably increased the creep strength of a similar material; the creep curves obtained by Senior $/ 15 /$ had a relatively long normal primary creep stage, and the creep rate attained a minimum value that is lower than in the a.r. and crept samples. This result could be expected due to the strengthening effect of the fine $\mathrm{NbC}$ particles in the $750^{\circ} \mathrm{C}$ aged steel (average particle dimension $4.5 \mathrm{~nm}$ ), which is more effective than in the solution-treated and crept samples of this study $(d=50 \mathrm{~nm}$ at $\mathrm{t}=600 \mathrm{~h})$.

\section{Creep Deformation in Cold Worked Material}

Increasing the cold working amount changed the shape of the creep curve, and a normal long primary creep stage appeared. This result is in direct contrast with previous observations on the creep response of

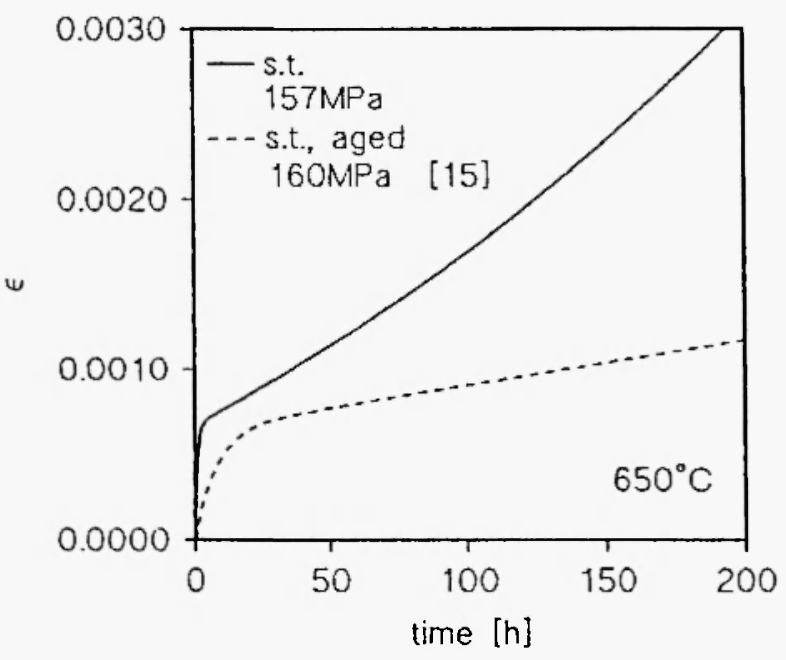

Fig. 13: Comparison between the creep response of the as received material and the creep curves obtained by Senior $/ 15 /$ under similar test conditions from an AISI 3/.7 aged steel. 
cold worked materials $125 /$, including stainless steel like the AISI 304 /26/. The pseudo-tertiary creep, typical of prestrained materials, was generally attributed to rearrangement of the dislocations introduced by cold working; on the other hand, the results of the present study suggest that the observed long primary creep corresponded to a sharp decrease in dislocation density, the shape of the $15 \%$ c.w. creep curves being similar to the one reported by Senior for the aged material. The similarities in the shape of the creep curves in solution-treated-c.w. and in solution-treatedaged materials seem to indicate that deformation is controlled by the same mechanism (presumably particle strengthening). Moreover, even if the free dislocation density decreased during creep, a fully recovered substructure was obtained only at a very high temperature $\left(825^{\circ} \mathrm{C}\right)$. On the other hand, in room $/ 26$ $29 /$ as well as in high /30/ temperature prestrained materials, where precipitation of fine $\mathrm{MX}$ is not expected, as in AISI 304 stainless steel, the Taylor hardening is the main strengthening mechanism, and the shape of the creep curve is exclusively controlled by evolution (i.e., re-arrangement) of dislocation in well defined substructures, leading to the onset of pseudotertiary creep.

\section{CONCLUSIONS}

Cold working significantly improved creep strength (time to rupture) but decreased rupture ductility; full recovery of microstructure, that led to a dramatic decrease in creep strength, was observed in the cold worked material only at the highest test temperature $\left(825^{\circ} \mathrm{C}\right)$.

This study attempted to establish the following qualitative interpretation of the creep behaviour of cold worked material between 625 and $725^{\circ} \mathrm{C}$ : after a sharp decrease in creep rate, which corresponded to an increase in dislocation density content, a long primary transient stage was accompanied by a recoverycontrolled decay of free dislocation density and by the precipitation of $\mathrm{NbC}$. The high initial dislocation density, in fact, promoted the nucleation of very fine $(<10 \mathrm{~nm}) \mathrm{NbC}$, that obstructed the slip of dislocations, reducing the re-arrangement in substructures. When the average dislocation link length was approximately equal to the interparticle spacing, the dislocation density attained a constant value, and deformation became climb-controlled, the fine particles being the most effective strengthening mechanism.

\section{ACKNOWLEDGEMENTS}

The authors sincerely thank Dr. J. Stobrawa for his contribution to TEM microscopy and greatly appreciate the support of ENEL, that partially funded this work under a research contract.

\section{REFERENCES}

1. J.M. Silcock, D. Raynor and G. Willoughby, Met. Sci., 11, 551 (1977).

2. B.F. Dyson and M.J. Rogers, Met Sci., 8, 261 (1974).

3. D.J. Powell, R. Pilkington and D.A. Miller, "The effect of prestrain on the creep and creep fatigue properties of a $20 \% \quad \mathrm{Cr}-25 \mathrm{Ni}-\mathrm{Nb}$ stabilized stainless steel", in: Proc. Second Inter. Conf. on Creep and Fracture of Engineering Materials and Structures, B. Wilshire and D.R.J. Owen (eds.), Swansea, U.K., Pineridge Press, 1984; p. 989.

4. K. Milicka, Met. Sci., 16, 419 (1982).

5. M.E. Kassner, J. Mat. Sci., 25, 1997 (1990).

6. W. Blum and B. Reppich, "Creep of particle strengthened alloys" in: Creep Behaviour of Crystalline Solids, B. Wilshire and R.W. Evans (eds.), Swansea, U.K., Pineridge Press, 1985; p. 83.

7. Shi Longquan and D.O. Northwood, J. Mat. Sci., 28, 5963 (1993).

8. Shi Longquan and D.O. Northwood, Acta Metall. et Mater., 41 (12), 3393 (1993).

9. S.R. Keown, "Microstructural changes occurring during the creep deformation of a simple austenitic steel at $600^{\circ} \mathrm{C}^{\prime \prime}$, in: Proc. of Creep Strength in Steel and High Temperature Alloys, Sheffield, Iron and Steel Institute, 1972; p. 78.

10. A. Orlova, J. Čadek, Met. Sci., 15, 39 (1981).

11. J.D. Cook, D.R. Harries and A.C. Roberts, "Some factors affecting the creep strength of $20 \% \mathrm{Cr}$ - 
$25 \% \mathrm{Ni}-\mathrm{Nb}$ austenitic steel at $750^{\circ} \mathrm{C} "$, in: Proc. of Creep Strength in Steel and High Temperature Alloys, Sheffield, Iron and Steel Institute, 1972; p. 91.

12. I. Ben-Haroe, A. Rosen and I.W. Hall, Mater. Sci. Tech., 9 (7), 620 (1993).

13. J.A. Todd and Ren Jyh-Ching, Mater. Sci. Eng., A117, 235 (1987).

14. T. Thorvaldsson and G.L. Dunlop, Met. Sci., 11, 513 (1980).

15. B.A. Senior, Mater. Sci. Eng., A124, 159 (1990).

16. R.C. Ecob, Acta Metall., 12, 2149 (1984).

17. R.C. Ecob and H.E. Evans, Acta Metall., 4, 805 (1987).

18. J. Wadsworth, S.R. Keown and J.H. Woodhead, Met. Sci., 3, 105 (1976).

19. W. Kesternich, Phil. Mag. A, 52, 533 (1985).

20. J.W. Martin, "Micromechanisms in particle hardened alloys", Cambridge Solid State Science Series, Cambridge University Press, 1987; p. 41.

21. S. Goto, "Particle shape effect on high temperature yield strength of dispersion hardened nickel base alloys", in: Proc. Creep and Fracture of Engineering Materials and Structures, B. Wilshire and R.W. Evans (eds.), Swansea, U.K., Pineridge Press, 1987; p. 295.

22. E. Evangelista, D. D'Angelo, L. Kloc, A. Rosen and S. Spigarelli, "Cold work effect on particle strengthening in creep of AISI 347 stainless steel", in: Proc. Materials for Advanced Power Engineering 1994, D. Coutsouradis et al. (eds.), Kluwer Academic Publishers, 1994; Vol. I, p. 485.

23. F. Dobeš and K. Milið ka Met. Sci., 11, 382 (1976).

24. E.E. Underwood, Quantitative Stereology, Reading, MA, Addison-Wesley, 1970.

25. H. Oikawa and T.G. Langdon, "The creep characteristics of pure metals and solid solution alloys", in: Creep Behaviour of Crystalline Solids, B. Wilshire and R.W. Evans (eds.), Swansea, U.K., Pineridge Press, 1985; p. 33.

26. O. Ajaja and A.J. Ardell, "The effect of prior cold work on the creep characteristics of AISI type 304 stainless steel", in: Proc. 4th International Conference on the Strength of the Metals and Alloys, Nancy, France, Ed. Laboratoire Physique du Solide, E.N.S.M.I.M., I.N.P.L., Parc de Saurupt, Nancy, 1976; p. 880.

27. O. Ajaja and J. Ardell, Scripta Metall., 11, 1089 (1977).

28. O. Ajaja and J. Ardell, Phil. Mag. A., 39, 65 (1979).

29. O. Ajaja and J. Ardell, Phil. Mag. A, 39, 91 (1979).

30. S. Kikuchi and B. Ilschner, Scripta Metall., 20, 159 (1986). 
